\title{
Recurrent abdominal pain in childhood
}

Fang Kuan $\underline{\mathrm{Chiou}}^{1}$, MBBS, MRCPCH, Choon How $\underline{\mathrm{How}}^{2}$, MBBS, FCFP, Christina $\underline{\text { Ong }}^{1}$, MBBs, FRCPCH

\begin{abstract}
Macey, together with her mother, presented to your clinic with complaints of recurrent abdominal pain of five months' duration. The pain, which occurred four to five times a week, had caused her to miss school on numerous occasions and this might affect her good performance in school. Her mother was worried that Macey might have a serious gut disease. Despite being only 12 years old, Macey was known to have a high pain threshold, and this had caused her mother to believe that her abdominal pain would have to be extremely severe for her to be affected by it.
\end{abstract}

\section{INTRODUCTION}

Chronic or recurrent abdominal pain (RAP) was defined by Apley and Naish in 1958 as the occurrence of at least three episodes of abdominal pain that is severe enough to affect a child's activities within a period of three months. ${ }^{(1)}$ In clinical practice, abdominal pain that lasts for more than one or two months is considered chronic. Despite its seemingly benign nature, RAP is associated with increased episodes of school absence, frequent visits to doctors, as well as considerable distress to the child and family. Even after decades of research, RAP remains a formidable challenge for the physician to manage.

\section{HOW COMMON IS RAP?}

RAP is a commonly encountered complaint in general practitioner and paediatrician clinics. Its prevalence ranges from $10 \%-45 \%$ in school-going children, ${ }^{(2)}$ and it accounts for $2 \%-4 \%$ of visits to primary care physician and up to $50 \%$ of visits to paediatric gastroenterologists. ${ }^{(3,4)}$ In 2004, Oh et al reported that the incidence of RAP in Singaporean children was around 23.4\%, with a mean patient age of 11.7 years (range 6-17 years) and a female preponderance $(62.4 \%) .^{(5}$

\section{MAKING SENSE OF RAP IN CHILDHOOD}

For practical purposes, RAP can be classified as either an organic or functional disorder. Early studies suggested that organic causes account for $5 \%-10 \%$ of RAP cases. ${ }^{(1,6)}$ The availability of more advanced investigative techniques has led to higher detection rates of organic disorder, which may be as high as 30\% in some recent studies. ${ }^{(7,8)}$ There are numerous organic causes of RAP, including constipation, acid peptic disease (e.g. gastritis, reflux oesophagitis, Helicobacter pylori infection),
Table I. Organic causes of chronic abdominal pain. ${ }^{(9)}$

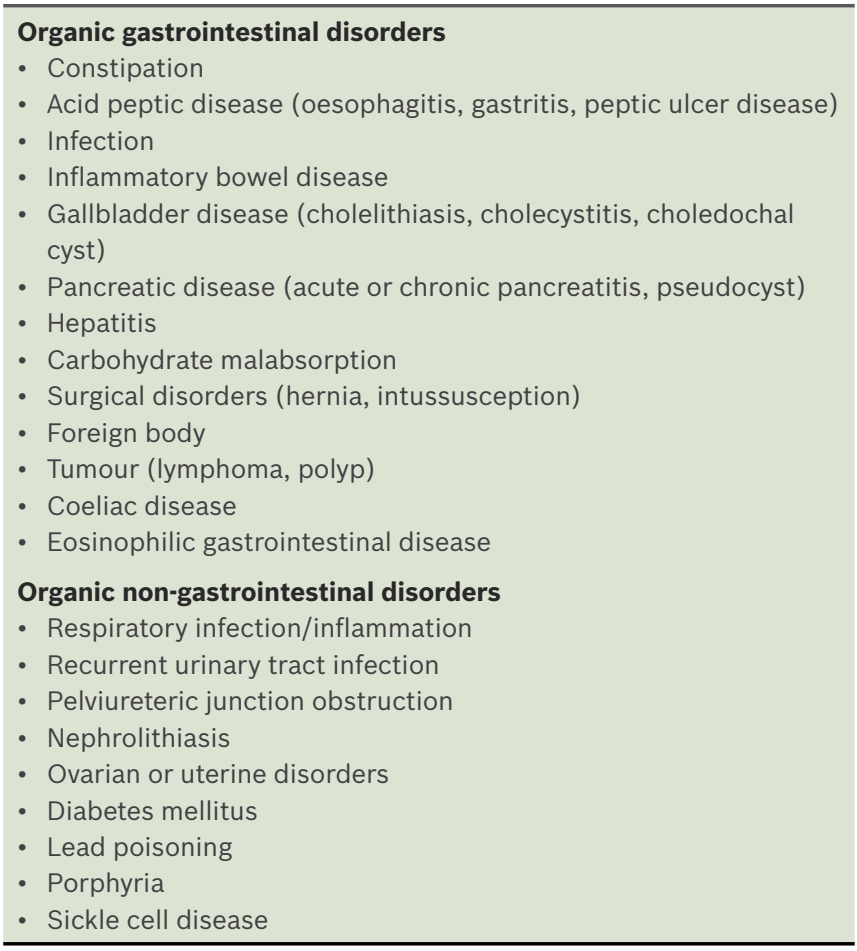

carbohydrate malabsorption and dysmenorrhoea. Less common aetiologies include urinary tract infection, inflammatory bowel disease, liver or gallbladder pathology and pancreatic disease (Table I).

In a child who complains of RAP, the physician may be sufficiently concerned to order investigations to avoid missing occult organic disease. However, in the majority of cases, RAP is due to functional pain or functional gastrointestinal disorder (FGID), i.e. abdominal pain without any demonstrable evidence

\footnotetext{
${ }^{1}$ Gastroenterology Service, Department of Paediatrics, KK Women's and Children's Hospital, Singapore, ${ }^{2}$ Sing Health Polyclinics - Sengkang, Singapore Correspondence: Dr Christina Ong, Head and Consultant, Gastroenterology Service, Department of Paediatrics, KK Women's and Children's Hospital, Level 3, Children's Tower, 100 Bukit Timah Road, Singapore 229899. christina.ong@kkh.com.sg
} 
Table II. Rome III criteria for childhood functional gastrointestinal disorders.

\begin{tabular}{|c|c|}
\hline $\begin{array}{l}\text { Functional } \\
\text { dyspepsia }\end{array}$ & $\begin{array}{l}\text { Must include all of the following: }{ }^{*,+} \\
\text { - Persistent or recurrent pain or discomfort } \\
\text { centred in the upper abdomen (above the } \\
\text { umbilicus) } \\
\text { - Not relieved by defaecation, or associated with } \\
\text { the onset of a change in stool frequency or form }\end{array}$ \\
\hline $\begin{array}{l}\text { Irritable bowel } \\
\text { syndrome }\end{array}$ & $\begin{array}{l}\text { Must include all of the following: }{ }^{*,+} \\
\text { - Abdominal discomfort (uncomfortable sensation } \\
\text { not described as pain), or pain associated with } \\
\geq 2 \text { of the following at least } 25 \% \text { of the time: } \\
\text { - Improvement with defaecation } \\
\text { - Onset associated with a change in frequency } \\
\text { of stool } \\
\text { - Onset associated with a change in form } \\
\text { (appearance) of stool }\end{array}$ \\
\hline $\begin{array}{l}\text { Functional } \\
\text { abdominal pain }\end{array}$ & $\begin{array}{l}\text { Must include all of the following: }:^{*,+} \\
\text { - Episodic or continuous abdominal pain } \\
\text { - Insufficient criteria for other functional } \\
\text { gastrointestinal disorders }\end{array}$ \\
\hline $\begin{array}{l}\text { Functional } \\
\text { abdominal pain } \\
\text { syndrome }\end{array}$ & $\begin{array}{l}\text { Must include functional abdominal pain at least } 25 \% \\
\text { of the time and } \geq 1 \text { of the following: } \\
\text { - Some loss of daily functioning } \\
\text { - Additional somatic symptoms such as headache, } \\
\text { limb pain or difficulty in sleeping }\end{array}$ \\
\hline $\begin{array}{l}\text { Abdominal } \\
\text { migraine }\end{array}$ & $\begin{array}{l}\text { Must include all of the following: }{ }^{*,} \\
\text { - Paroxysmal episodes of intense, acute } \\
\text { periumbilical pain that lasts for } \geq 1 \text { hour } \\
\text { - Intervening periods of usual health lasting weeks } \\
\text { to months } \\
\text { - Pain interferes with normal activities } \\
\text { - Pain is associated with } \geq 2 \text { of the following: } \\
\text { anorexia; nausea; vomiting; headache; } \\
\text { photophobia; pallor }\end{array}$ \\
\hline
\end{tabular}
12 months.

of an underlying pathology. The Rome III criteria( ${ }^{(10)}$ classify FGID into five categories: functional dyspepsia, irritable bowel syndrome, functional abdominal pain, functional abdominal pain syndrome and abdominal migraine (Table II). Although these criteria allow the categorisation of patients into definable subgroups based on the symptoms they display, their practical value in clinical management and prognosis has yet to be validated.

\section{What causes RAP in children?}

The pathogenesis of RAP in children remains poorly understood. Visceral hypersensitivity, gastrointestinal (GI) dysmotility, inflammation, psychological factors and family dynamics have all been suggested as contributory factors. There is growing evidence that functional abdominal pain may be associated with visceral hyperalgesia, which refers to a decreased threshold for pain in response to changes in the gut intraluminal pressure. ${ }^{(11,12)}$ The mucosal inflammatory process - caused by infection, allergic response or underlying inflammation - may have sensitised the gut afferent nerves, and has been associated with the onset of visceral hypersensitivity. In this group of children, normal peristaltic movement of the gut may be perceived as painful sensations, which can be debilitating in certain cases. This concept can best be explained to the patient as being akin to the sensation one experiences after a burn or injury - the skin remains sensitive for a prolonged period of time and normal stimuli that are not usually uncomfortable (such as contact with clothes) become a noxious sensation.

Emotional disorders have been postulated to alter the interaction between the central nervous system and enteric nervous system, also known as the 'brain-gut axis', resulting in visceral hypersensitivity and RAP. ${ }^{(2)}$ Early life events, such as abdominal surgery during infancy, history of Henoch-Schonlein purpura and cow's milk protein allergy, are also associated with FGID, presumably due to similar changes in the brain-gut axis. ${ }^{(12)}$ GI motility disorder is another important contributing factor in functional abdominal pain. Dysmotility of the gut has been well documented in specific conditions such as irritable bowel syndrome and functional dyspepsia. ${ }^{(12)}$ Abnormally strong intestinal contractions and distension of the Gl tract cause abdominal bloating and discomfort in the child, who perceives the sensation as abdominal pain.

\section{HOW DO PSYCHOSOCIAL FACTORS INFLUENCE RAP?}

Psychosocial factors, including life stressors, emotional distress, a timid personality and poor coping skills, are linked to the development and perpetuation of RAP. Parental perception and response to a child's symptom is an important contributory factor to his/her recovery from RAP. A study of patients hospitalised for RAP concluded that a child was more likely to recover from symptoms of RAP at follow-up if the parents had attributed the pain to psychological factors. ${ }^{(13)}$ In addition, children with RAP, whose parents also suffered from similar functional Gl disorders, tended to have high frequency of physician visits and school absence compared to children whose parents did not have Gl symptoms.

Macey pointed to the periumbilical region when asked where the pain was most intense. You also found out that the pain lasted a few seconds to an hour each time and that it usually occurred in the morning when she was preparing to go to school but never at night during sleep. She had not experienced any vomiting. Other than the occasional hard stool, she had no change in bowel habit and had not noticed any blood in her stools. Macey's mother reported that the child had been eating well with no noticeable weight loss. There was no family history of gastrointestinal disease.

\section{EVALUATING THE CHILD WITH RAP}

There are two important aims in the initial assessment of a child with RAP. First, we aim to determine if the abdominal pain is attributable to an organic or functional disorder. Second, we aim to identify triggering factors associated with the pain, including psychosocial factors, dietary habits and bowel patterns. As with 
Table III. Alarm symptoms and signs.

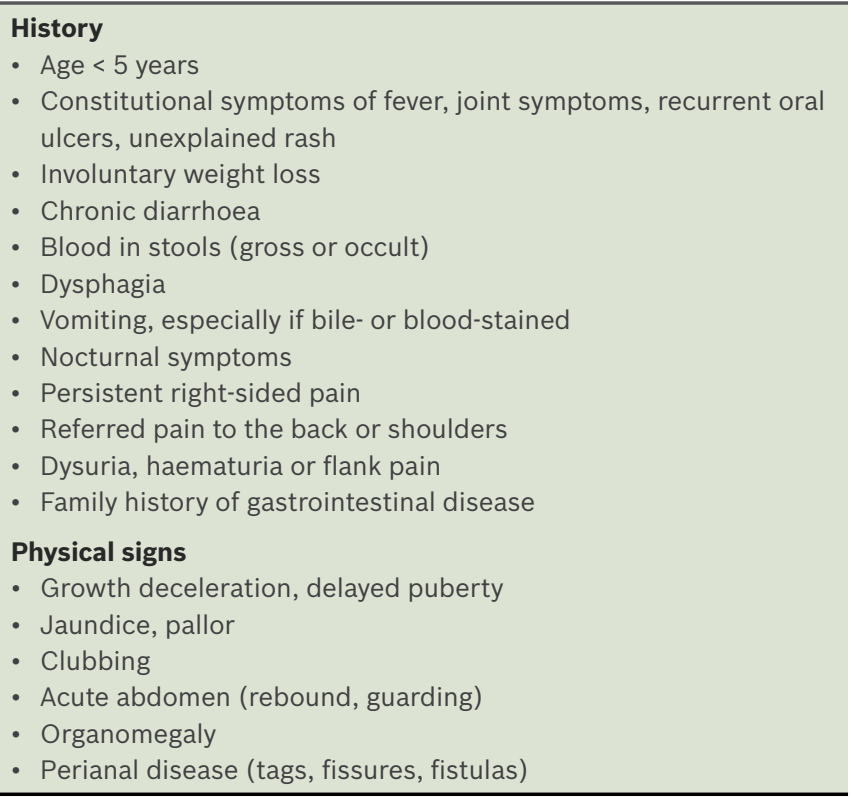

any medical condition, thorough history-taking and physical examination are crucial. As far as possible, history should be obtained directly from the child to minimise the influence of parental interpretation or perception in symptom reporting. Apart from the GI history, the physician should also enquire about any psychological stressors, as well as the impact of the symptoms on activities and school attendance.

In almost all cases of functional abdominal pain, clinical examination would be unremarkable, without any alarm symptoms or signs (Table III). Most of these cases do not warrant further routine investigations. Gieteling et al reported that negative test results in children with functional GI disorders usually do not give reassurance to parents, but paradoxically reinforce their fear of an unknown organic disease. ${ }^{(14)}$ The presence of alarm symptoms and signs, on the contrary, suggests a greater likelihood of an organic disorder, which justifies further diagnostic investigations and referral to a paediatric GI specialist. ${ }^{(3)}$

\section{Laboratory investigations}

An initial workup may include full blood count, liver function test and inflammatory marker measurement. A normal blood test does not necessarily exclude organic GI disease. Second-tier laboratory tests can be considered for specific patients, depending on the nature of the abdominal pain. Children presenting with dyspepsia can undergo a noninvasive screen for Helicobacter pylori, such as the urea breath test. Urinalysis and urine culture may be performed in patients with lower abdominal pain. In patients with altered bowel habits (e.g. increased stool frequency or consistency) stool bacterial culture, parasite identification and stool occult blood test should be considered.

\section{Imaging and endoscopic studies}

Plain abdominal radiography has a limited role in the routine workup for RAP. Abdominal and pelvic ultrasonography is more

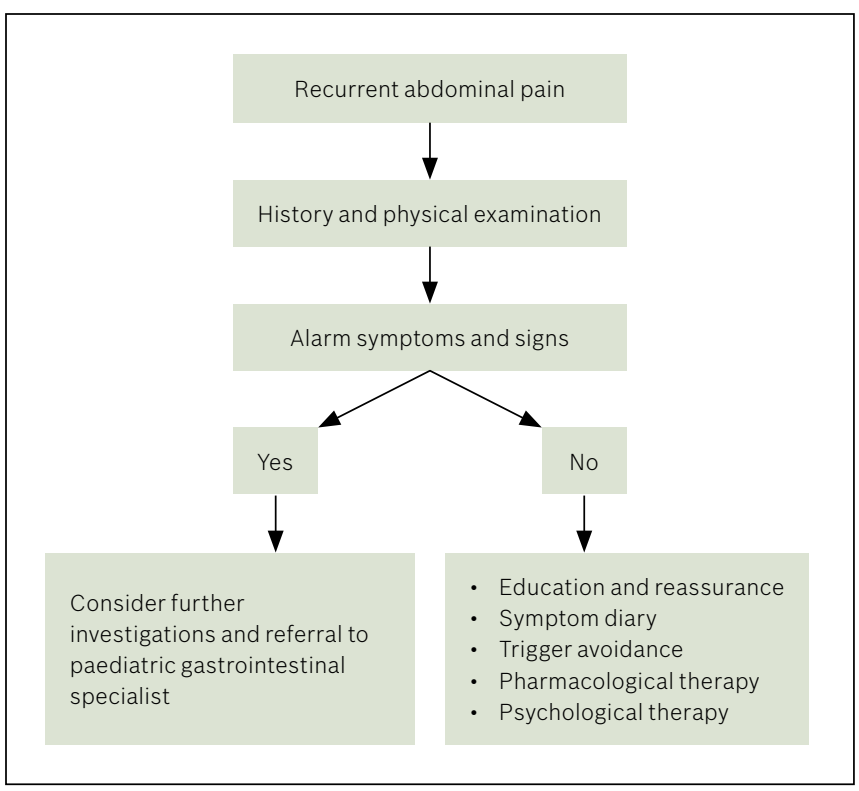

Fig. 1 Algorithm shows the clinical approach to a child with recurrent abdominal pain.

likely to detect an abnormal pathology if there are alarm features such as jaundice, urinary symptoms or abnormal abdominal signs. Upper and/or lower endoscopy is reserved for patients in whom an underlying Gl pathology is suspected.

\section{PRACTICAL APPROACH TO MANAGING RAP WITHOUT ALARM SYMPTOMS AND SIGNS IN CHILDREN}

\section{Reassurance and setting of realistic goals}

Education and reassurance are the key steps in managing a child with RAP. The physician should reassure the child and family that chronic abdominal pain is a common symptom in children and that few have an underlying disease. It may be helpful to explain that the recurrent pain is normally caused by an increased sensation from the activation of the nerves in a healthy gut, using hyperalgesia of a healing scar, or increased Gl symptoms like vomiting or diarrhoea prior to major examinations, as examples. Realistic treatment goals should be set, with the main aim being the return to normal function rather than a complete resolution of the symptoms.

\section{Abdominal pain diary: the patient and family takes responsibility}

The child is encouraged to maintain a symptom diary by recording any triggering factors, duration of pain and accompanying symptoms such as vomiting and altered bowel habits. Causative dietary triggers such as dairy products, spice and caffeine should be identified and avoided where possible.

\section{Pharmacotherapy}

Pharmacological therapy is frequently used to treat RAP, with varying results. Commonly used agents include acid suppressing drugs (histamine receptor antagonists, proton pump inhibitors), antispasmodic drugs (trimebutine), analgesics and probiotics. 
Medications should be individualised based on symptoms and discontinued if no improvement is seen after a trial of therapy.

\section{Psychological therapy}

In many instances, all that is needed is reassurance from the doctor that there is no serious underlying disease. Psychological intervention may have a role in difficult cases, where there is a complex interaction between the child's psychosocial background and abdominal symptoms. Cognitive behavioural therapy aims to modify thoughts, beliefs and behavioural responses to symptoms, and has been shown to improve pain and disability outcome in various studies. ${ }^{(3)}$ Relaxation training is another modality that attenuates the physiologic effects of stress and anxiety, hence relieving Gl symptoms in patients with RAP. ${ }^{(11)}$

You summarised the normal findings from your detailed examination of Macey and concluded that she had a functional Gl disorder. You explained to Macey's mother that the exaggerated signals from the nerves in her child's gut occur in many healthy people. You also shared the possible contributing factors that could worsen the pain, such as stress, certain food and medications. Macey was taught how to use an abdominal pain diary, prescribed with probiotics and advised to adhere to a balanced diet. On subsequent visits, Macey showed a gradual improvement in her symptoms, with fewer missed days from school. Macey and her mother also noticed a pattern - the pain was always transient and usually occurred before class assessments. As this was Macey's final year at primary school, her pain could possibly be attributed to the stress of having to perform well in school and in not letting her mother down with results that were less than her very best.

\section{OUTCOME OF CHILDREN WITH RAP}

While most children with RAP eventually experience a complete resolution of symptoms, a recent meta-analysis suggested that nearly $30 \%$ of these children will continue to have persistent abdominal pain at a median follow-up period of five years. ${ }^{(14)}$ Such patients may continue to be symptomatic in adulthood and may even develop other symptoms such as chronic recurrent headache. These children are also more likely to develop irritable bowel syndrome ${ }^{(15)}$ and anxiety disorders in adulthood. ${ }^{(2)}$

\section{TAKE HOME MESSAGES}

1. Childhood RAP is a commonly encountered complaint in general practitioner and paediatrician clinics.

2. A majority of children with RAP do not have an underlying organic cause.

3. Initial evaluation focuses on eliciting alarm symptoms and signs to differentiate organic from functional disorders.
4. In the absence of alarm symptoms and signs, further diagnostic tests are usually not indicated.

5. The key to treating RAP of functional origin is education and reassurance.

6. A symptom diary helps patients and caregivers identify and minimise triggering factors.

7. Pharmacological and psychological therapies are adjunctive treatment options and should be tailored to the individual patient's symptoms and response.

8. Referral to a paediatric GI specialist should be considered if the patient has alarm symptoms and signs that require further evaluation.

ABSTRACT Recurrent abdominal pain in childhood is common, and continues to be a diagnostic and therapeutic challenge. It is usually attributed to a functional gastrointestinal disorder rather than an organic disease. In most cases, a comprehensive history and physical examination should enable one to make a positive diagnosis of functional disorder. The presence of alarm symptoms and signs, such as weight loss, gastrointestinal bleeding and chronic severe diarrhoea, warrants further investigations and referral to a paediatric gastrointestinal specialist. The mainstay of therapy in functional abdominal pain is education, reassurance and avoidance of triggering factors. While symptom-based pharmacological therapy may be helpful in patients who do not respond to simple management, it is best used on a time-limited basis due to the lack of good evidence of its efficacy. The primary goal of therapy is a return to normal daily activities rather than complete elimination of pain. In recalcitrant cases, psychological interventions such as cognitive behaviour therapy and relaxation training have proven to be efficacious.

Keywords: childhood, functional abdominal pain, functional gastrointestinal disorder, recurrent abdominal pain

\section{REFERENCES}

1. Apley J, Naish N. Recurrent abdominal pains: a field survey of 1000 school children. Arch Dis Child 1958; 33:165-70.

2. Plunkett A, Beattie RM. Recurrent abdominal pain in childhood. J R Soc Med 2005; 98:101-6.

3. Di Lorenzo C, Colletti RB, Lehmann HP, et al. Chronic abdominal pain in children: a technical report of the American Academy of Pediatrics and the North American Society for Pediatric Gastroenterology, Hepatology and Nutrition. J Pediatr Gastroenterol Nutr 2005; 40:249-61.

4. Nurko S, Di Lorenzo C. Functional abdominal pain: time to get together and move forward. J Pediatr Gastroenterol Nutr 2008; 47:679-80.

5. Oh MC, Aw MM, Chan YH, Tan LZ, Quak SH. Epidemiology of recurrent abdominal pain among Singaporean adolescents. Ann Acad Med Singapore 2004; 33(5 Suppl):S10-1.

6. Weydert JA, Ball TM, Davis MF. Systematic review of treatments for recurrent abdominal pain. Pediatrics 2003; 111:e1-11.

7. El-Matary W, Spray C, Sandhu B. Irritable bowel syndrome: the commonest cause of recurrent abdominal pain in children. Eur J Pediatr 2004; 163:584-8.

8. Hyams JS, Treem WR, Justinich CJ. Characterization of symptoms in children with recurrent abdominal pain: resemblance to irritable bowel syndrome. J Pediatr Gastroenterol Nutr 1995; 20:209-14. 
9. McFerron BA, Waseem S. Chronic recurrent abdominal pain. Pediatr Rev 2012; 33:509-17.

10. Rasquin A, Di Lorenzo C, Forbes D, et al. Childhood functional gastrointestinal disorders: child/adolescent. Gastroenterology 2006; 130:1527-37.

11. Mahajan LA, Kaplan B. Chronic abdominal pain of childhood and adolescence. In: Wyllie R, Hyams JS, eds. Pediatric Gastrointestinal and Liver Disease. 4th ed. Philadelphia: Elsevier Saunders, 2011: 66-79.

12. Miranda A. Early life events and the development of visceral hyperalgesia. J Pediatr Gastroenterol Nutr 2008; 47:682-4.
13. Crushell E, Rowland M, Doherty M. Importance of parental conceptual model of illness in severe recurrent abdominal pain. Pediatrics 2003; $112(6$ Pt 1):1368-72.

14. Gieteling MJ, Bierma-Zeinstra SM, Passchier J, Berger MY. Prognosis of chronic or recurrent abdominal pain in children. J Pediatr Gastroenterol Nutr 2008; 47:316-26.

15. Chitkara DK, van Tilburg MA, Blois-Martin N, Whitehead WE. Early life risk factors that contribute to irritable bowel syndrome in adults: a systematic review. Am J Gastroenterol 2008; 103:765-74. 


\section{SINGAPORE MEDICAL COUNCIL CATEGORY 3B CME PROGRAMME}

\section{(Code SMJ 201304A)}

1. Recurrent abdominal pain (RAP) can be diagnosed if there are at least three episodes of abdominal pain that is severe enough to affect the child's activities within three months.

2. RAP is associated with increased school absence, frequent visits to doctors and significant distress to the child and family.

3. In 2004, it was reported that nearly a quarter of Singaporean children who experienced RAP had a mean age of 11.7 years.

4. Studies suggest that organic causes can be found in 5\%-30\% of symptomatic patients.

5. The Rome III criteria classify functional abdominal pain in children with validated effective clinical management for each of the five categories.

6. The pathogenesis of RAP in children can be contributed by visceral hypersensitivity, gastrointestinal (GI) dysmotility, inflammation, psychological factors and family dynamics.

7. Early life events, such as abdominal surgery during infancy, history of Henoch-Schonlein purpura and cow's milk protein allergy, are associated with functional Gl disorders.

8. Life stressors, emotional distress, a timid personality and poor coping skills are usually not linked to RAP.

9. Children whose parents suffer from functional GI disorders tend to have less physician visits and school absence, as their parents know how to cope better.

10. Children are usually poor at giving history, so doctors should direct their questions directly to the parent or caregiver to facilitate the history-taking process.

11. Apart from GI history, psychological stressors, and impact of symptoms on activities and school attendance are important components of history-taking.

12. It has been reported that negative test results in children with functional GI disorders are often reassuring to the children and their parents.

13. The presence of alarm symptoms and signs is associated with a greater likelihood of an organic disorder.

14. An initial workup for RAP may include full blood count, liver function test and inflammatory markers.

15. Children presenting with recurrent dyspepsia can be considered for a noninvasive screen for Helicobacter pylori.

16. Urinalysis and urine culture may be performed in children with recurrent lower abdominal pain.

17. Supine plain abdominal radiography is the recommended first-line imaging modality in the routine workup for RAP.

18. In the management of RAP, a diary for recording symptoms and causative dietary triggers can be helpful in determining the frequency and pattern of attacks, and possible triggers to avoid.

19. Education and reassurance are the key steps in managing a child with RAP.

20. A realistic treatment goal - a return to normal function - should be set, as more than $20 \%$ of children with RAP continue to have persistent abdominal pain for up to five years after diagnosis.

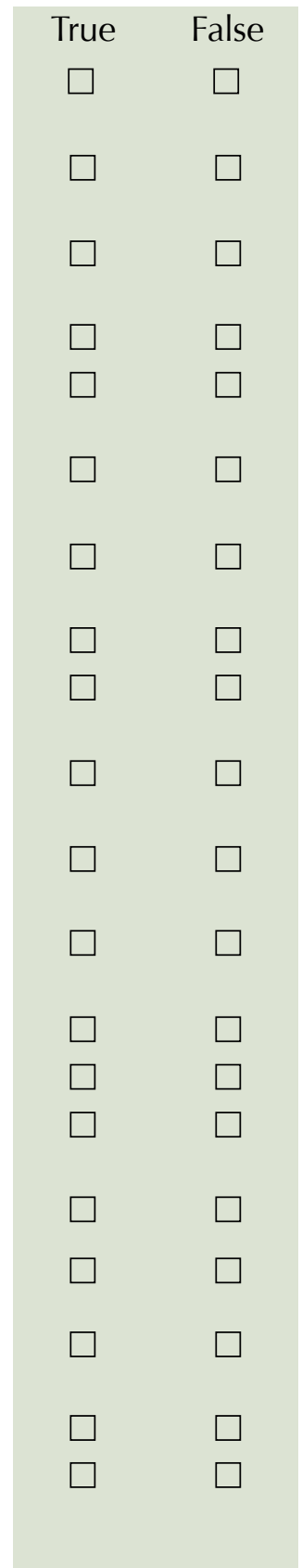

\section{Doctor's particulars:}

Name in full

MCR number

Specialty:

Email address

SUBMISSION INSTRUCTIONS:

(1) Log on at the SMJ website: http://www.sma.org.sg/cme/smj and select the appropriate set of questions. (2) Select your answers and provide your name, email address and MCR number. Click on "Submit answers" to submit.

RESULTS:

(1) Answers will be published in the SMJ June 2013 issue. (2) The MCR numbers of successful candidates will be posted online at www.sma.org.sg/cme/smj by 27 May 2013. (3) All online submissions will receive an automatic email acknowledgement. (4) Passing mark is $60 \%$. No mark will be deducted for incorrect answers. (5) The SMJ editorial office will submit the list of successful candidates to the Singapore Medical Council. (6) One CME point is awarded for successful candidates. 